\title{
Preparedness and Readiness Against COVID-19 Pandemic in Prison Institutions and Detention Centers in Southwest Ethiopia
}

This article was published in the following Dove Press journal: International Journal of General Medicine

Besufekad Mekonnen (D) Shewangizaw Hailemariam ${ }^{2}$

Amare Ejigu $\mathbb{D}^{2}$

Nigusie Shifera $\mathbb{D}^{3}$

Asnake Simieneh ${ }^{4}$

'Department of Public Health, Mizan-Tepi University, Mizan-Aman, Southern Nation Nationality and People Region, Ethiopia; ${ }^{2}$ Department of Midwifery, Mizan-Tepi University, Mizan-Aman, Southern Nation Nationality and People Region, Ethiopia; ${ }^{3}$ Department of Nursing, Mizan-Tepi University, Mizan-Aman, Southern Nation Nationality and People Region, Ethiopia; ${ }^{4}$ Department of Medical Laboratory, Mizan-Tepi University, Mizan-Aman, Southern Nation Nationality and People Region, Ethiopia
Correspondence: Besufekad Mekonnen Department of Public Health, Mizan-Tepi University, PO Box: 260, Mizan-Aman, Southern Nation Nationality and People Region, Ethiopia

Tel +251905193372

Email besusweet 12@gmail.com
Background: Prisons and detention centers in Ethiopia lack adequate hand washing, personal protective equipment, and quarantine areas. As a result, they are vulnerable to the expansion of the COVID-19 pandemic. Despite its high risk for the COVID-19 pandemic, no study has been made to assess the preparedness and readiness in prison institutions and detention centers.

Methods: A cross-sectional study design mixed with a qualitative approach was conducted from May 1 to June 30, 2020. A total of four prison institutions and 17 detention centers were included in the study. A simple random sampling technique was employed to select the institutions. The data were entered into the EpiData and exported to SPSS Windows version 22 for data management and analysis. Descriptive statistics was employed for the quantitative section and content analysis was used to analyze the qualitative data.

Results: Five out of 17 detention centers and three out of four prison facilities did not fulfill the standards related to human rights. Almost all detention centers and prison facilities did not implement recommended activities of risk assessment and management of COVID-19. In addition, none of the prison facilities and detention centers had quick access to laboratory tests for suspected cases. Neither the prison facilities nor the detention centers had a contingency plan for the COVID-19 pandemic. Moreover, all staff working in prison facilities and detention centers mentioned that training regarding COVID-19 had not yet been given. However, in all prisons and detention centers, preventive measures such as physical distancing, utilization of hand washing facilities, wearing masks, and keeping respiratory hygiene were not practiced.

Keywords: preparedness, readiness, prisons, detentions, novel coronavirus disease

\section{Introduction}

Novel coronavirus disease 2019 (COVID-19) is phylogenetically in the SARS-CoV -2 clade an infectious disease that spread quickly and reached approximately 214 countries in the world. ${ }^{1}$ Worldwide, 36,401,583 people were affected by this infection, and 1,060,567 died as of October 8, 2020. In Ethiopia, the first case was detected on March 13, 2020.,3 The total numbers of cases, recoveries, and deaths as of October 8, 2020 were 80,895, 35,670 and 1225, respectively. Ethiopia is one of the developing Sub-Saharan African countries facing the double burden of infectious and noninfectious diseases. ${ }^{4}$ On top of this, the current pandemic of COVID-19 brings additional frustration to the country. 5,6

The world's prison population is estimated at around 11 million, with rates of incarceration ranging from 698 per 100,000 population in the United States to as 
low as 16 per 100,000 in the Central African Republic. ${ }^{7}$ In Ethiopia, there are approximately 113,727 people incarcerated. $^{8}$

People destitute of their liberty, such as people in prison institutions and detention centers, are likely to be more vulnerable to the coronavirus disease (COVID-19) outbreak than people who live outside because of the cramped conditions in which they live together for long periods. ${ }^{9}{ }^{10}$ Moreover, the current situation shows that in prison and detention facilities, people incarcerated gathered in close proximity may act as a source of infection, magnification, and spread of infectious diseases like COVID-19 within and beyond prisons and detention centers. ${ }^{11,12}$ Prison health is, therefore, generally considered public health. ${ }^{10,13}$

Most prison institutions and detention centers were built to take full advantage of public safety; not to minimize the transmission of communicable disease or to competently deliver health-care services. ${ }^{14}$ The probability of transmission of potentially infectious diseases such as COVID-19 are increased by crowding, ${ }^{15}$ interruptions in medical evaluation and treatment, inadequate resource and limited access to soap, water, and clean laundry, insufficient infection-control expertise and prohibitions against the use of proven harm reduction tools. ${ }^{13,16}$ Besides, many prisons and detention centers lack sufficient information technology; clinical information-sharing between institutions and the different jurisdictions responsible for the care of inmates is often poor. ${ }^{9}$ The high prevalence of mental illness among prisoners and detainees often complicates the proper management of contagious illnesses like the COVID-19 pandemic. ${ }^{17-19}$

The systemic neglect of prisons and other places of detention in many countries have resulted in inadequate resources, management, oversight and accountability mechanisms, including ill-equipped personnel, and limited links to public health systems. Prison overcrowding persists in most countries and constitutes one of the most fundamental obstacles to providing safe and healthy custodial environments in line with fundamental human rights. ${ }^{20,21}$ Confined accommodation, unhygienic conditions, ventilation, and nutrition as well as inadequate health-care services in many prison systems will in the same way challenge infection control measures and thus considerably raise the risk for infection, increase and spread of COVID-19. ${ }^{22,23}$

The majority of prisoners and detainees will eventually return to their families. Therefore, the situation of a rapid increase transmission of COVID-19 within prisons and detention centers will have an amplifying effect on the epidemic within the total population. ${ }^{24,25}$ The high turnover of prisoners being admitted and released as well as the daily interaction of prisoners with prison officers, health-care professionals, visitors and service providers all provide for an intrinsic link between prisons and public health. ${ }^{24,26,27}$ On these grounds, any control strategy for COVID-19 in the community that does not embrace the prison institution and detention center context will not be sustainable. $^{9}$

In Ethiopia, the Ministry of Peace and Federal Prison Administration is in charge of health in prisons. The central government and the authorities of the regions have contingency plans for COVID-19 prevention and control, which is a suspension of the visits of family members and progressive isolation from the external community. However, it does not embrace the adoption of practices to identify possible cases and to treat infected subjects. In regional prisons, conditions are much worse because of greater overcrowding, poor hygiene, and environmental conditions (poor ventilation system, indiscriminate disposal of solid and liquid waste, limited access to bathroom and toilet facilities, and insufficient supply of safe water) and inadequate medical facilities. ${ }^{28}$

Confirmed COVID-19 cases among prisoners and prison officers have been reported in many parts of the world, including Ethiopia. This number, however, is almost certain to increase alarmingly in the future. In addition, the burden is already high in prison institutions and detention centers around the world due to the introduction of other restrictions, such as the suspension of prison visits and furloughs. ${ }^{29,30}$ In Ethiopia, the federal and regional governments decided to pardon to more than 40,000 prisoners in an effort to hold the spread of COVID-19, focusing on those with a maximum sentence of less than one year and approaching their release, elderly prisoners, including women detainees with children and expectant mothers. ${ }^{23}$ There is no evidence regarding the total number of cases and deaths in prison facilities in Ethiopia.

However, to date, there are plenty of prisons and detention centers in Ethiopia, including Bench-Sheko, Sheka, West Omo, and Kaffa prison institutions, which have been living in gathering ways and uncomfortable situations. In addition, prisons and detention centers often lack sufficient hand washing areas, quarantine rooms, and personal protective equipment. ${ }^{31,32} \mathrm{As}$ a result, they are vulnerable to the transmission of COVID-19. Therefore, the aim of this research was to 
answer a research question, whether the correctional facilities were prepared and ready against COVID-19 pandemic in Bench-Sheko, Sheka, West Omo, and Keffa zones southwest, Ethiopia.

\section{Materials and Methods}

\section{Study Area and Period}

The study was conducted in Bench-Sheko, Sheka, West Omo, and Kaffa zones from May 1 to June 30, 2020. Bench-Sheko zone which is one of the 16 zones in the Southern Nation Nationality and Regional state, it is located $585 \mathrm{~km}$ away from Addis Ababa, the center of Ethiopia, in a southwest direction with an estimated population of 829,493 and the primary health service coverage of the zone is $92.6 \%$, covering a total catchment area of $19,965.8 \mathrm{~km}^{2}$ with the majority $86 \%(1,061,120)$ of the population living in the rural areas. The zone has about 39 functional health centers. The zone, has one prison institution and eight detention centers having more than 2500 prisoners.

Kaffa zone is located at $468 \mathrm{~km}$ from Addis Ababa, the capital city of Ethiopia. Administratively, the zone has 10 districts and one town administration. Based on the 2007 census of the central statistical agency of Ethiopia (CSA), the total population of the zone was estimated to be $1,171,133$, of whom 578,151 (49.4\%) were males and $592,982(50.6 \%)$ were females. This zone has one general public hospital, one primary hospital, and 43 public health centers. There are 12 detention centers and one prison institution with 2500 prisoners in the zone.

Sheka zone is located approximately $700 \mathrm{~km}$ southwest of Addis Ababa. The geographical condition of the area lies between $07^{\circ} 07.49 \dot{4}$ to $07^{\circ} 52.301 \mathrm{~N}$ and $035^{\circ} 16.576$ to $035^{\circ} 39.516 \mathrm{E}$ with altitudinal ranges of 950 to 2780 . This zone has one general public hospital, six public health centers, and one prison institution, five detention centers and having more than 1200 prisoners.

West Omo zone is a newly established zone of the South Nation Nationalities and Peoples of Ethiopian Regional State which has seven districts and 116 kebeles (112 rural and four urban), with a total population of 272,943 constituting $12 \%$ of regional populations and inhabited by a pastoral community of $135,025(49.47 \%)$ male, 137,918 (50.53\%) rural resident 243,738 (89.3\%) urban residents 28,113 (10.7\%). The total households are 55,703 . Regarding health infrastructure, this zone has two hospitals and 13 health centers, 94 health posts which make the zone basic health service coverage $90 \%$ and health centers and health posts coverage $98 \%$ and $90 \%$ respectively and one prison institution, nine detention centers and having more than 2000 prisoners.

\section{Population and Study Design}

A cross-sectional study design mixed with qualitative approach was conducted. All prisons and detention centers found in in Bench-Sheko, Sheka, West Omo and Kaffa zones were taken as the source population, while randomly selected detention centers and all prisons found in BenchSheko, Sheka, West Omo, and Kaffa zones were considered as the study population.

\section{Sampling Size and Sampling Techniques}

The four prisons found in the zones and $50 \%$ of the detention centers were included. During the selection of detention centers simple random sampling technique was used, first, the list of all detention centers found in each district was obtained from respective zonal administration then, using the list of detention centers as a sampling frame $50 \%$ of the detention centers were selected randomly giving 17 detention centers.

\section{Data Collection and Quality Control}

Interview guide and observational checklist were adapted from WHO for evaluation of risk assessment and management techniques. It has eight sub-themes: human rights, risk assessment and management, referral system and clinical management, contingency planning, training, risk communication, preventive measures, and case management of the prison institutions and detention centers against COVID-19. ${ }^{25}$ This tool was validated by WHO and recommended to assess correctional facilities readiness against COVID-19 pandemic.

As part of ensuring the quality of the data, a pretest was conducted on $5 \%$ of the detention centers which were not included in the study. Accordingly, an amendment was made based on the result of the pretest. The interview was conducted with open-ended question with purposively selected 50 prisons and detention center's top managers and team leaders such as chief executive of prisons (4), head of detention centers (17), shift coordinators (21), head of prison clinics (4), and head of the prison cafeteria (4).

The data were collected by four BSc nurses after providing extensive training on the objective of the study, contents of the questionnaire, data collection procedure, infection prevention and control techniques including 
proper use of personal protective equipment. The data collection process was supervised by three health-care professionals having a BSc degree in public health. Supervision was made on the daily basis, checking completeness, and consistency of the collected data was made.

\section{Data Analysis}

The data were cleaned, edited, coded, and entered into EpiData manager, and exported to SPSS software version 25. Descriptive statistics (frequency and percentage) were used to describe each item under the sub-themes of WHO risk assessment checklist. The final result was presented using tables. Qualitative data were transcribed verbatim, translated to English language, and analyzed with Open code version 4.02 software and content analysis was followed. Codes and categories were developed and findings were summarized by supporting with quotes from respective study participants. Moreover, the data coded by researchers independently and we brought the codes together to see intercoder consistency.

\section{Ethical Consideration}

Ethical approval letter was granted from Mizan-Tepi University Ethical Review Board. The official letter of cooperation was obtained from the zonal health bureau. Before conducting the interviews, information was given to the participants, and respondents were assured of voluntary participation, confidentiality, anonymity and freedom to withdraw from the study at any time. In addition, the objective of the study was explained with the nature of the study and associated risk and benefit. Moreover, the verbal informed consent was approved by the Mizan-Tepi University Ethical Review Board, and this study was conducted in accordance with the Declaration of Helsinki.

\section{Results}

\section{Human Rights}

Based on assessment of the facilities in implementing protocols of health service accessible for people in prison facilities comparable to those in the general population; five out of 17 detention centers and three out of four prison facilities fulfill the standards. Based on observed basic living standards (space, fresh air, light, and sanitation), neither prison facilities nor detention centers provided appropriate services. All prison facilities and detention centers permitted people in prison more than one hour of outside activities daily. In one prison facility and three detention centers noncustodial actions for the running of criminal justice were being used (eg electronic tagging and physical exercise). Moreover, the following are part of responses from study participants:

Even though the number of prisoners was reduced after decided pardon by the federal and regional governments, prisoners are living in a very crowded place. In this situation, it is difficult for us to practices coronavirus prevention measures such as keeping physical distance. (A chief executive of prison study participant)

I have encountered some prisoners presented with anxiety, after they were done compulsory physical exercise and beaten up by prison officials. (A head of prison clinic study participant)

\section{Risk Assessment and Management}

Regarding risk assessment and management, none of the detention centers and only two of the prison facilities had indepth archives of people moving in and out of the facility. Again, none of the detention centers and only one of the prison facilities had risk assessment held on people entering the facility. The facilities also claimed that the assessment is being undertaken even on prison officers entering the facility at each access. However, none of the facilities had a dedicated area for risk assessment (Table 1). The key informants added to this issue saying:

I think it is important to undertake risk assessment on every individual before entering prison and detention centers; however, we do not have dedicated screening area and assigned health personnel to do so. (A head of prison clinic study participant)

Unlike prison facilities, detention centers do not have clinics and health personnel to care for detainees. As a result, we are facing challenges to undertake different measures and risk assessment related to corona virus. (A head of detention center study participant)

\section{Referral System and Clinical Management}

Prisons' and detention centers' health personnel were asked if there was quick access to laboratory test in case they encounter suspected case; and all of the prison and detention centers reported that they did not have this. Only two of the prison facilities mentioned that laboratory-confirmed cases had access to quarantine and management. But the quarantines were not adequate and not as per the national protocol. All the prison and detention center staffs mentioned that health-care teams dealing with the collection of biological 
Table I Risk Assessment of COVID-19 in Prison and Management of COVID-19 in Prison Institutions and Detention Centers of Bench-Sheko, Sheka, Kaffa, and West Omo Zones 2020 (n=2I)

\begin{tabular}{|c|c|c|c|c|c|}
\hline \multirow[t]{2}{*}{ No. } & \multirow[t]{2}{*}{ Risk Assessment and Management } & \multicolumn{2}{|c|}{$\begin{array}{l}\text { Detention } \\
\text { Center }(n=17)\end{array}$} & \multicolumn{2}{|c|}{$\begin{array}{l}\text { Prison } \\
(n=4)\end{array}$} \\
\hline & & Yes & No & Yes & No \\
\hline I & Is there in-depth archive of all people moving in and out of prison? & 0 & 17 & 2 & 2 \\
\hline 2 & Are risk assessments held on all people entering the prison? & 0 & 17 & 1 & 3 \\
\hline 3 & Are such assessments undertaken in the case of prison officers entering the facility, at each access? & 0 & 17 & I & 3 \\
\hline 4 & Is there a committed area for these risk assessments? & 0 & 17 & 0 & 4 \\
\hline 5 & Is information on symptoms over the previous seven days collected as part of this risk assessment? & 0 & 17 & I & 3 \\
\hline 6 & Is evidence gathered on recent contact with possible cases (over previous I4 days)? & 0 & 17 & 0 & 4 \\
\hline 7 & $\begin{array}{l}\text { Is information on travel limits and appearance of symptoms on condition that to prison officers so that } \\
\text { they can inform the designated health-care providers? }\end{array}$ & 2 & 15 & I & 3 \\
\hline 8 & $\begin{array}{l}\text { Is advice on contact restrictions and presence of symptoms provided to visitors well in advance of their } \\
\text { arrival at the prison? }\end{array}$ & 5 & 12 & NA & NA \\
\hline 9 & Are asymptomatic individuals prevented from visiting if they meet any of the criteria for exclusion? & 1 & 16 & 1 & 3 \\
\hline 10 & Are symptomatic visitors excluded from visits & 0 & 17 & NA & NA \\
\hline II & Has some arrangement to allow non-contact visits (e.g. Skype or phone) been set up? & 0 & 17 & NA & NA \\
\hline
\end{tabular}

Abbreviation: NA, not applicable.

samples had no access to the essential protective equipment as described in the WHO prison guideline (Table 2). One of the study participants described his concern on this issue as follows:
Despite having referral system and clinical management recommended by national protocol, we do not have a functional laboratory, clinical management, and referral system in our facility. (A chief executive of prison study participant)

Table 2 Referral System and Clinical Management of Prisoners in Prison Institutions and Detention Centers of Bench-Sheko, Sheka, Kaffa, and West Omo Zones $2020(\mathrm{n}=21)$

\begin{tabular}{|c|c|c|c|c|c|}
\hline \multirow[t]{2}{*}{ No. } & \multirow[t]{2}{*}{ Referral System and Clinical Management } & \multicolumn{2}{|c|}{$\begin{array}{l}\text { Detention } \\
\text { Center } n=I 7\end{array}$} & \multicolumn{2}{|c|}{$\begin{array}{l}\text { Prison } \\
n=4\end{array}$} \\
\hline & & Yes & No & Yes & No \\
\hline I & Do suspected cases have quick access to laboratory tests? & 0 & 17 & 0 & 4 \\
\hline 2 & Do laboratory-confirmed cases have access to quarantine and management? & 0 & 17 & 2 & 2 \\
\hline 3 & $\begin{array}{l}\text { Do contacts of laboratory-confirmed cases have access to places for adequate quarantine according to } \\
\text { national protocols? }\end{array}$ & 0 & 17 & 0 & 4 \\
\hline 4 & $\begin{array}{l}\text { Do health-care teams dealing with the collection of biological samples have access to the essential preventive } \\
\text { protective equipment as described in WHO prison guidance? }\end{array}$ & 0 & 17 & 0 & 4 \\
\hline 5 & Are prison authorities made alert of the hospitals to which they can transfer those necessitating admission? & 0 & 17 & 0 & 4 \\
\hline 6 & Are there clear standards for shifting severely ill patients to hospital? & 17 & 0 & 4 & 0 \\
\hline 7 & $\begin{array}{l}\text { Are there etiquettes in place to manage patients' onsite (if they do not meet the standards for transfer to } \\
\text { hospital)? }\end{array}$ & 17 & 0 & 4 & 0 \\
\hline 8 & Are there any actions in place to evade gathering of people in prison? & 0 & 17 & 0 & 4 \\
\hline
\end{tabular}




\section{Contingency Planning}

All prison facilities and detention centers had no contingency plans for managing the impact of an infectious disease outbreak in advance. In addition, national comprehensive risk assessment of the prison and detention system had not yet been assessed. Regarding personal protective equipment (PPE), all the prisons and detention centers mentioned inadequate PPE for use by prisoners and detainees. Furthermore, assessment of the need for PPE and other essential supplies were not carried out in all facilities. Moreover, the following are part of the responses from study participants:

We have faced a serious shortage of supplies, particularly; we do not have enough personal protective equipment for prisoners and staffs as well. (A head of prison clinic study participant)

We have not made any need assessment regarding personal protective equipment, particularly; glove, mask and hand washing sanitizer. (A head of detention center study participant)

\section{Training}

Staffs working in prison facilities and detention centers had not received training on basic COVID-19 disease knowledge, hand washing practices, and respiratory etiquette. In addition, they were not trained on the appropriate use of personal protective equipment (PPE) and environmental prevention measures, including cleaning and disinfection. Moreover, all detention centers had not taken any action to disseminate information broadly among people in detentions, while only one out of four prison facilities assessed had taken action to disseminate information related to COVID19 through local mass media. The key informants strengthened this issue saying:

We have not received any training yet regarding coronavirus prevention and control measures in our prison facility; we heard about the issue from social Media and mass Medias. (A head of prison cafeteria study participant)

In our detention center, we have not made any attempt to disseminate information related to preventive measures of the coronavirus for detainees, because we do not have sufficient knowledge and materials to do so. (A head of detention center study participant)

\section{Risk Communication}

Five of the prison facilities and three of the detention centers reported the presence of a contact approach to deal with public and risk communication about disease outbreaks in prison. None of the detention centers and three of the prison facilities claimed to have a mechanism to gather and integrate the risk perception of people in prison, staff, and visitors in message development. Key messages were communicated in a clear, accurate and relevant manner to people in prison facilities about preventive measures, especially hand hygiene and respiratory good manners in almost all prisons and detention centers. However, information on COVID-19 was not accessible through relevant channels and tools were not conveyed by trusted influencers/mediators in all facilities (Table 3). One of the study participants stated the concern as follows:

We have made an effort to communicate the prisoners on frequent hand washing and keeping respiratory hygiene, but detail information on the nature of coronavirus disease was not communicated yet. (A head of prison clinic study participant)

\section{Prevention Measures}

Regarding prevention measures, there is no standard in place to handle officers who meet the definition of a suspected or confirmed case in all prisons and detention centers. In all facilities there are routines and facilities that allow hands to be washed with soap and water and dried using single-use towels. But there is no wall-mounted liquid-soap, paper towels, and facilities in place that allow appropriate physical distancing (Table 4). In addition, one of them described the concern as follows:

In different corners of the prison facility, there are posted material reminding hands to be washed with soap and water, however, we do not have other necessary materials such as paper towel and face mask. (A chief executive of prison study participant)

\section{Case Management}

All detention centers and prison facilities were not integrated into the local/national epidemiological surveillance system. Besides, neither detention centers nor prison facilities had isolated and single accommodation places, facilities designated exclusively as well as health-care professionals assigned to care for suspected and identified COVID-19 cases according to national protocols. One of the study participants explained the issue as follows: 
Table 3 Risk Communication of COVID-19 in Prison Institutions and Detention Centers of Bench-Sheko, Sheka, Kaffa, and West Omo Zones, $2020(n=21)$

\begin{tabular}{|c|c|c|c|c|c|}
\hline \multirow[t]{2}{*}{ No. } & \multirow[t]{2}{*}{ Risk Communication } & \multicolumn{2}{|c|}{$\begin{array}{l}\text { Detention } \\
\text { Center } \\
n=17\end{array}$} & \multicolumn{2}{|c|}{$\begin{array}{l}\text { Prison } \\
\mathrm{n}=4\end{array}$} \\
\hline & & Yes & No & Yes & No \\
\hline I & Is there a contact approach to deal with public and risk communication about disease outbreaks in prison? & 5 & 12 & 3 & I \\
\hline 2 & $\begin{array}{l}\text { Is there a mechanism to gather and integrate the risk perception of people in prison, staff and visitors in } \\
\text { message development? }\end{array}$ & 0 & 17 & 3 & I \\
\hline 3 & $\begin{array}{l}\text { Are key messages communicated in a clear, accurate and relevant manner to people in prison facilities about } \\
\text { preventive measures, especially hand hygiene and respiratory good manners? }\end{array}$ & 15 & 2 & 4 & 0 \\
\hline 4 & $\begin{array}{l}\text { Are key messages communicated in a clear, accurate and relevant manner to people in prison facilities about } \\
\text { disease signs and symptoms, including warning signs of severe disease requiring instant medical attention? }\end{array}$ & 10 & 7 & 3 & I \\
\hline 5 & $\begin{array}{l}\text { Is information on COVID-19 accessible through relevant channels and tools and as conveyed by trusted } \\
\text { influencers/mediators? }\end{array}$ & 0 & 17 & 0 & 4 \\
\hline 6 & $\begin{array}{l}\text { Are the items detailed in } 2-4 \text { available in formats that take account of possible language and cultural barriers } \\
\text { and disabilities? }\end{array}$ & 0 & 17 & 0 & 4 \\
\hline
\end{tabular}

Table 4 Prevention Measures of COVID-19 in Prison Institutions and Detention Centers of Bench-Sheko, Sheka, Kaffa, and West Omo Zones, 2020 ( $n=21)$

\begin{tabular}{|c|c|c|c|c|c|}
\hline \multirow[t]{2}{*}{ No. } & \multirow[t]{2}{*}{ Prevention Measures } & \multicolumn{2}{|c|}{$\begin{array}{l}\text { Detention } \\
\text { Center } \\
n=17\end{array}$} & \multicolumn{2}{|c|}{$\begin{array}{l}\text { Prison } \\
\mathrm{n}=4\end{array}$} \\
\hline & & Yes & No & Yes & No \\
\hline I & Are there standards in place to handle officers who meet the definition of a suspected or confirmed case? & 0 & 17 & 0 & 4 \\
\hline 2 & $\begin{array}{l}\text { Are there routines and facilities that allow hands to be washed with soap and water and dried using single-use } \\
\text { towels? }\end{array}$ & 17 & 0 & 4 & 0 \\
\hline 3 & Are wall-mounted liquid-soap providers available in communal areas such as toilets and showers? & 0 & 17 & 0 & 4 \\
\hline 4 & Are paper towels available in these areas? & 0 & 17 & 0 & 4 \\
\hline 5 & Are there routines and facilities in place that allow appropriate physical distancing? & 0 & 17 & 0 & 4 \\
\hline 6 & Are there medical masks available for confirmed cases or suspected cases with symptoms (eg a cough)? & 0 & 17 & 0 & 4 \\
\hline 7 & $\begin{array}{l}\text { Are there facilities that let any person in prison suspected of having COVID-19, based on risk assessment, to } \\
\text { be placed in isolation, in single accommodation, according to national rules? }\end{array}$ & 0 & 17 & 3 & I \\
\hline 8 & $\begin{array}{l}\text { When quarantined, are people in prison medically detected at least twice a day (including testing and recording } \\
\text { of symptoms and temperature)? }\end{array}$ & 0 & 17 & 0 & 4 \\
\hline 9 & Are staffs with COVID-I9 symptoms encouraged to stay at home and seek medical attention as necessary? & 0 & 17 & 0 & 4 \\
\hline
\end{tabular}

If we encounter suspected case, there is no clear structure to communicate with a concerned body. Also, there is no isolation and quarantine center in our facility to manage suspected case. (A head of prison clinic study participant)

\section{Discussion}

People in prison facilities and detention centers are highly vulnerable to communicable diseases. ${ }^{7,12,33}$ Prisoners and detainees in those facilities live in close proximity with 
one another which likely increases the risk of person-toperson and droplet transmission of pathogens like COVID$19 .^{34}$ This aim of this study was to assess preparedness, prevention and control of COVID-19 in prison facilities and detention centers.

In this study, most prison facilities and some detention centers had not provided standards of health care for prisoners and detainees. This is inconsistent with the WHO recommendation, which states the supply of appropriate health-care services for all people in prisons and detention centers to be given without insight on the grounds of their legal status. ${ }^{8,25}$ This might be due to resource insufficiency associated with poor financing of correctional institutions and other administration issues. In all studied facilities, people in prisons were allowed more than one hour of outdoor activities daily. This finding is in line with WHO and UNODC standards. ${ }^{21,25}$

Regarding basic living standards for people in prison, none of the facilities provided appropriate service. This finding contradicts WHO recommendation on the handling of prisons. ${ }^{13,25}$ This might be related to inappropriate construction of facilities that did not consider criteria of enough space, fresh air, light, and sanitation.

Although WHO recommends that prisons and detention centers have a full registry of all people moving in and out of the facility, ${ }^{25}$ almost all of the detention centers and two out of the four prisons facilities had not made an effort to have a full registry of all people moving in and out of the facility as presented in Table 1. As part of an endeavor to tackle the rapid spread of the virus in highly vulnerable places like prisons and detention centers, it is imperative to undertake risk assessment on all people entering the prison and detention facilities and there should also be a dedicated place to do so. ${ }^{25}$ However, contrary to this general direction, all detention centers and three of the prison facilities did not comply with this standard. Moreover, they did not have a dedicated place to do so. Poor infrastructural setup coupled with inadequate awareness about the COVID-19 pandemic among the prison staff might be the reason why standards are not being met.

In this COVID-19 pandemic period, as a precautionary measure, all prison facilities found in the study area did not allow any visitors access to the facilities. Nonetheless, in all detention centers it was possible for visitors to get access into the detention centers, before entering into the detention centers, only five of the detention centers would give advice on contact restrictions and presence of symptoms to visitors well in advance as presented in Table 2. In this COVID-19 pandemic, visitors are prohibited from access the prison facility, unless the need for visiting is approved by the prison's higher officials. ${ }^{13,23}$ Unlike prisons facilities, detention centers allowed visitors into the facilities. Before entering to the facilities, only five of the detention centers gave advice for visitors with symptom on contact limits. Only one detention center precludes asymptomatic individuals from visiting if they meet any of the criteria for exclusion. In this regard, only one of 17 detention centers fully complies with the WHO recommendation. ${ }^{25}$

In our assessment, none of the prison facilities and detention centers had quick access to laboratory tests for suspected cases, and adequate quarantine, took action to avoid concentration of people as well as access to the necessary preventive protective equipment according to national protocols and WHO prison guidance. Currently, only two prison facilities had access to isolation and management in a medical facility for laboratory-confirmed cases (Table 1).

Prison and detention staff and facilities in the study area have not received any training related to COVID-19 and the result is far from WHO recommendation. ${ }^{9,13}$ It is stated that before embarking on any initiative, it is fully important for the prison staff to participate in widespread information and awareness-raising activities, so that people in prison facilities, detention centers, and visitors are informed in advance and know the procedures to be adopted, why they are essential, and how they are to be carried out. It is particularly crucial that any possible limiting measures are explained and their temporary nature emphasized. ${ }^{10}$

In this study, the majority of detention centers and prison facilities made key messages linked in a clear and important manner about the pandemic signs and symptoms and prevention measures as presented in Table 3. This finding is consistent with WHO and UNODC guidelines which stated that key messages for people in prison and detention facilities, health service providers and visitors must be coordinated. $^{23,25}$ This might be due to a clear awareness of the risk of an outbreak.

As indicated in Table 4, preventive measures of COVID-19 such as availability of protocol, hand washing basin, sanitation equipment, respiratory etiquette, and physical distancing were not practiced in all detention centers and prison facilities in the study area. The result is far 
from WHO recommendation in which all staff and people in prisons and detention facilities should have wideranging awareness of COVID-19 prevention strategies, including obedience to hand hygiene measures, respiratory etiquette, physical distancing (keeping a distance of at least two meters from others), being alert to signs and symptoms of COVID-19, staying away from ill people, and (in the case of staff) staying home when ill. ${ }^{8,9,25}$ The observed gaps could be attributable to lack of resources, finance, and training programs.

\section{Conclusion and Recommendation}

The intent of the present study was to address the preparedness and readiness of correctional facilities to combat COVID-19 pandemic in a low resource setting area particularly in southwest Ethiopia. The result revealed that prisons and detention facilities found in Bench-Sheko, Kaffa, Sheka, and West Omo zones have demonstrated less preparedness and readiness to COVID-19 pandemics compared with WHO recommendations. Notably, prison and detention facilities have made little effort in addressing the following preventive measures: risk assessment and management, referral system and clinical management, contingency planning, prevention measures, training for staff, and risk communication, which are WHO recommendations for highly vulnerable places like prisons and detention centers.

Federal and regional prison administrations, Police Commissions, Ministry of Health and other relevant entities working in prevention and control of COVID-19 pandemic, should focus on endeavoring to alter prison environments in the way that suits the WHO recommendations, prevent noncustodial measures and safeguard the right of prisoners and detainees. In addition, the federal government should mobilize resources and allocate adequate COVID-19 related budget to prison and detention facilities. Moreover, upcoming educational interventions are recommended for staff, prisoners and detainees to raise awareness of this disease and should be focused on rural detention centers and prison institutions which lack information and facilities. Likewise, educational messages should be more simplified and understandable in their ethnic languages. Moreover, frequent communication is recommended between detention and prison staff, health-care providers and the public to help to avoid empirical preventive measures and response to the disease and to empower the prison and detention staff with the information. Finally, further studies are suggested to explore the potential reasons for ineffective response to the COVID19 pandemic in correctional facilities of Ethiopia.

\section{Data Sharing Statement}

The data that support the findings of this study are available from the corresponding author upon reasonable request.

\section{Acknowledgment}

The authors acknowledge Mizan Tepi University for unreserved support. In addition, the authors express their appreciation and thanks to Mizan-Tepi University research and community service directorate for overall facilities during the survey. Lastly, the researchers would like to extend their deepest thanks to all staff of College of Health Sciences in MTU, for their valuable comments.

\section{Funding}

The authors acknowledged Mizan-Tepi University for financial support.

\section{Disclosure}

The authors report no conflicts of interest in this work.

\section{References}

1. Spagnuolo G, De VD, Rengo S, Tatullo M. COVID-19 outbreak: an overview on dentistry. Int J Environ Res Public Health. 2020;17:1-3.

2. Wondimu W, Girma B. Challenges and silver linings of COVID-19 in Ethiopia - short review. J Multidiscip Healthc. 2020;13:917-922. doi:10.2147/JMDH.S269359

3. Ranjan R, Ranjan GK, College NN, Narayan G. Knowledge regarding prevention of novel Coronavirus (COVID-19): an electronic cross-sectional survey among selected rural community. Int $J$ Trend Sci Res Dev. 2020;4(3):422-426.

4. Abuya T. COVID-19-related knowledge, attitudes, and practices in urban slums in Nairobi, Kenya: study description. Soc Behav Sci Res. 2020;4(3):1-7.

5. Alzoubi H, Alnawaiseh N, Lubad A, Aqel A, Al H. COVID-19 Knowledge, attitude and practice among medical and Non-Medical University students in Jordan. J Pure Appl Microbiol. 2020;14 (1):17-24. doi:10.22207/JPAM.14.1.04

6. Shi Y, Wang J, Yang Y, et al. Knowledge and attitudes of medical staff in Chinese psychiatric hospitals regarding COVID-19. Brain Behav Immun. 2020;4(March). doi:10.1016/j.bbih.2020.100064

7. Nijhawan AE. Infectious diseases and the criminal justice system: a public health perspective. Am J Med Sci. 2017;352(4):399-407. doi:10.1016/j.amjms.2016.05.020.Infectious

8. Franco-paredes C, Jankousky K, Schultz J, et al. COVID-19 in jails and prisons: a neglected infection in a marginalized population. PLoS Negl Trop Dis. 2020;14(6):9-12. doi:10.1371/journal.pntd.0008409

9. Montoya-barthelemy AG, Lee CD, Cundiff DR, Smith EB. COVID19 and the Correctional Environment: The American Prison as a Focal Point for Public Health. Vol. 58. Elsevier Inc.; 2020. doi:10.1016/j.amepre.2020.04.001

10. Cingolani M, Caraceni L, Cannovo N, Fedeli P. The COVID-19 epidemic and the prison system in Italy. $J$ Correct Health Care. 2020;1-8. doi:10.1177/1078345820929733

11. Simpson PL, Simpson M, Adily A, Grant L, Butler T. Prison cell spatial density and infectious and communicable diseases: a systematic review. BMJ. 2019;9:1-10. doi:10.1136/bmjopen-2018026806 
12. Tavoschi L, Vroling H, Madeddu G, et al. Active case finding for communicable diseases in prison settings: increasing testing coverage and uptake among the prison population in the European Union/ European Economic Area. Epidemiol Rev. 2018;40:105-120. doi:10.1093/epirev/mxy001

13. Bick JA. Infection control in jails and prisons. Health Epidemiol. 2016;45(15):1047-1055. doi:10.1086/521910

14. Tozzo P, Angiolella GD, Caenazzo L. Forensic science international: synergy prisoners in a pandemic: we should think about detainees during Covid-19 outbreak. Forensic Sci Int Synergy. 2020;2:162-163. doi:10.1016/j.fsisyn.2020.05.004

15. Simpson PL, Butler TG. Covid-19, prison crowding, and release policies. BMJ. 2020;369(April):1-2. doi:10.1136/bmj.m1551

16. Murdoch DJ. British Columbia provincial corrections' response to the COVID-19 pandemic: a case study of correctional policy and practice. Vict Offender. 2020;1-20. doi:10.1080/15564886.2020.1829225

17. Australian Institute of Health and Welfare. The Health of Australia's Prisoners 2015. Australian Institue of Health and Welfare; 2015.

18. Schwartz J, Yen M. Toward a collaborative model of pandemic preparedness and response: Taiwan's changing approach to pandemics. $J$ Microbiol Immunol Infect. 2017;50(2):125-132. doi:10.1016/j.jmii.2016.08.010

19. Binswanger IA, Blatchford PJ, Mueller SR, Stern MF. Mortality after prison release: opioid overdose and other causes of death, risk factors, and time trends from 1999 to 2009. Ann Intern Med. 2017;159(9):592-600. doi:10.7326/0003-4819-159-9-201311050-00005.Mortality

20. Henry BF. Social distancing and incarceration: policy and management strategies to reduce COVID-19 transmission and promote health equity through decarceration. Health Educ Behav. 2020;47 (4):536-539. doi:10.1177/1090198120927318

21. United Nations Office on Drugs and Crime. Good Governance for Prison Health in the 21st Century. WHO Regional Office for Europe; 2020.

22. Control EC for DP and. Outbreak of Novel Coronavirus Disease 2019 (COVID-19): Increased Transmission Globally - Fifth Update What is New in This Update. Vol. 2019. 2020.

23. UNODC. Position paper on COV I D - 19 preparedness and responses in prisons. 2020. Available from: https://www.unodc.org/ documents/hiv-aids/publications/UNODC_position_paper_COVID19_in_prisons_-_FINAL.pdf. Accessed January 15, 2021.
24. Binswanger IA, Carson EA, Krueger PM. Prison tobacco control policies and deaths from smoking in United States prisons: population based. BMJ. 2014;349(August):1-12. doi:10.1136/bmj.g4542

25. WHO. Preparedness, Prevention and Control of COVID-19 in Prisons and Other. New. WHO Regional Office for Europe; 2020.

26. Abbott $\mathrm{P}$, Lloyd JE, Joshi C, et al. Do programs for aboriginal and torres strait islander people leaving prison meet their health and social support needs ? Aust J Rural Health. 2017;26:1-8. doi:10.1111/ajr.12396

27. Manderson L, Levine S. COVID-19, risk, fear, and fall-out. Med Anthropol. 2020;39(5):367-370. doi:10.1080/01459740.20 20.1746301

28. Ramanathan K, Antognini D, Combes A, et al. Decarceration and community re-entry in the COVID-19 era. Lancet Infect Dis. 2020; January:19-21. doi:10.1016/S1473-3099(20)30730-11

29. Services UD of $\mathrm{H}$ and H. COVID-19 in Correctional and Detention Facilities. Vol. 69. 2020.

30. Saloner B, Parish K, Ward JA, DiLaura G, Dolovich S. COVID-19 cases and deaths in federal and state prisons. JAMA. 2020;324 (6):602-603. doi:10.1056/NEJMp2014836

31. Mamo Y, Asefa A, Qanche Q, Dhuguma T, Wolde A, Nigussie T. Perception toward quarantine for COVID-19 among adult residents of selected towns in Southwest Ethiopia. Int $J$ Gen Med. 2020;13:991-1001. doi:10.2147/IJGM.S277273

32. Shigute Z, Mebratie AD, Alemu G, Bedi A. Containing the spread of COVID-19 in Ethiopia. J Glob Health. 2020;10(1):1-4. doi:10.7189/ JOGH.10.010369

33. ECDC. Systematic Review on Active Case Finding of Communicable Diseases in Prison Settings. European Center for Disease Prevention and Control; 2017.

34. Kinner SA, Jesse T, Young KS, Louise Southalan DL-A, Carina Ferreira-Borges ÉO. Prisons and custodial settings are part of a comprehensive response to COVID-19. Lancet Public Health. 2019;5:188-189. doi:10.1016/S2468-2667(20)30058-X

\section{Publish your work in this journal}

The International Journal of General Medicine is an international, peer-reviewed open-access journal that focuses on general and internal medicine, pathogenesis, epidemiology, diagnosis, monitoring and treatment protocols. The journal is characterized by the rapid reporting of reviews, original research and clinical studies across all disease areas. The manuscript management system is completely online and includes a very quick and fair peer-review system, which is all easy to use. Visit http://www.dovepress.com/ testimonials.php to read real quotes from published authors.

Submit your manuscript here: https://www.dovepress.com/international-journal-of-general-medicine-journal 